\title{
Adverse effects of COVID-protective face-masks and wearing durations onto respiratory-haemodynamic physiology and exhaled breath constituents
}

\author{
Pritam Sukul ( $\sim$ pritam.sukul@uni-rostock.de) \\ University Medicine Rostock (UMR), Germany https://orcid.org/0000-0001-5114-1776 \\ Julia Bartels \\ University Medicine Rostock (UMR), Germany \\ Patricia Fuchs \\ University Medicine Rostock (UMR), Germany \\ Phillip Trefz \\ University Medicine Rostock (UMR), Germany \\ Rasmus Remy \\ University Medicine Rostock (UMR), Germany \\ Leo Rührmund \\ University Medicine Rostock (UMR), Germany \\ Svend Kamysek \\ University Medicine Rostock (UMR), Germany \\ Jochen K Schubert \\ University Medicine Rostock (UMR), Germany https://orcid.org/0000-0002-0956-9506 \\ Wolfram Miekisch \\ University Medicine Rostock (UMR), Germany https://orcid.org/0000-0003-1619-0315
}

\section{Research Article}

Keywords: FFP2 and surgical mask, Breathomics, SARS-CoV-2, Respiratory and hemodynamic effects, side effects, Pandemic policy, PTR-ToF-MS, Volatile organic compounds (VOCs)

Posted Date: September 28th, 2021

DOl: https://doi.org/10.21203/rs.3.rs-930030/v1

License: () (i) This work is licensed under a Creative Commons Attribution 4.0 International License. Read Full License

Version of Record: A version of this preprint was published at European Respiratory Journal on February 15th, 2022. See the published version at https://doi.org/10.1183/13993003.00009-2022.

\section{EDITORIAL NOTE:}

28 September 2021: This pilot study describes the results of an observational experiment conducted on 30 adult subjects, investigating the effect of surgical and FFP2 masks on a number of cardiopulmonary parameters and exhaled volatile metabolites. The researchers reported a significant and consistent decrease in peripheral oxygen saturation and an increase in partial $\mathrm{CO} 2$ pressure, which was most pronounced for elderly subjects and with the use of FFP2 masks. They also observed significant changes in hemodynamics and breath metabolites. Limitations of the study include a limited sample size, inclusion of only healthy participants, absence of blood oxygen measurement, and inability to generalize conclusions to fabric masks. The 
authors do not disclose any conflicts of interest. At the time of this posting, the World Health Organization recommends the use of non-medical, fabric masks by healthy people under the age of 60 and medical masks for people aged 60 and over or those with underlying health conditions. 


\section{Abstract}

While protecting against the coronavirus transmission, face-masks may have adverse effects on respiratory-haemodynamic parameters. We investigated immediate and progressive effects of FFP2 and surgical masks on exhaled breath constituents and physiological attributes in 30 healthy volunteers at rest.

We continuously monitored exhaled breath profiles in the mask space in elderly (age: 60-80 years) and adults (age: 20-60 years) over a period of 30 min by high-resolution real-time mass-spectrometry (PTR-ToF-MS). Peripheral oxygen saturation, respiratory-and haemodynamic parameters were measured (non-invasively) continuously in parallel.

Profound and consistent decrease in $\mathrm{SpO}_{2}$ and increase in $\mathrm{pET}-\mathrm{CO}_{2}$ indicates ascending deoxygenation and inadequate ventilation in subjects. Cardiac output and MAP changed as secondary. Exhalation of blood-borne volatile metabolites mirrored behaviour of cardiac output, $\mathrm{MAP}, \mathrm{SpO}_{2}$, respiratory rate and $\mathrm{pET}-\mathrm{CO}_{2}$. FFP2 masks affected more pronouncedly than surgical masks. Elderly cohort was more vulnerable to those effects. Exhaled humidity increased and exhaled oxygen decreased significantly over time. Breath profiles of endogenous aldehydes, hemiterpene, organosulfur, short-chain fatty acids, alcohols and ketone indicated cross-talks between physiometabolic effects such as hypoxia, oxidative stress, hypoventilation, compartmental vasoconstriction, altered systemic bacterial activity and energy homeostasis. Concentrations of exogenous VOCs such as aromatics, nitrile and monoterpene depicted compartmental storage and washout.

Breathomics allows unique physio-metabolic insights into side effects of face-mask wearing. Mask induced deoxygenation, oxidative stress, $\mathrm{CO}_{2}$ rebreathing, vasoconstriction and blood pressure fluctuations in elderly were clinically concerning (as leading towards hypoxia and hypoventilation). Intelligible global-pandemic policies should reconsider the type and wearing durations of recommended face-masks, based upon age and/or cardio-pulmonary conditions.

\section{Introduction}

Since early 2020 , face masks have gradually become an integral part of our new-normal lifestyle in order to protect us from air/breath borne transmission of SARS-CoV-2 infection[1, 2]. During the second wave of the pandemic, use of surgical and/or FFP2/N95/KN95 masks turned out as strictly mandatory attributes while in public. National and/or global policy makers have recommended even adapting FFP3 masks for further protection considering the emerging CoV-2 variants[3, 4]. In Germany, government has recommended use of FFP2 masks up to $75 \mathrm{~min}$ at a stretch and use of surgical mask throughout one's presence in the public and the same guidelines are applied for school attending children as well as for elderly (aged $>60$ years).

While protecting us from the COVID-19 transmission, masks are inducing variable side effects on our cardiorespiratory physiology[57], broncho-pulmonary gas-exchange[8] and in vivo metabolic processes. Studies have shown variable effects of surgical masks on cardiopulmonary parameters, $\mathrm{O}_{2}-\mathrm{CO}_{2}$ homeostasis, blood pH and thermoregulation etc[9]. Studies have also shown that conditions such as resistive breathing and/or hypoxia driven hyperventilation, respiratory alkalosis and increased oxidative stress can cause immediate immune suppression[10,11] as well as may lead to metabolic alkalosis[12]. A recent pilot observation of mask driven cardiopulmonary effects in 12 healthy subjects (age: $40.8 \pm 12.4$ years) at rest and during exercise, are interpreted as significant but modest[7]. However, it could not offer an insight into such effects in elderly subjects and also into metabolic changes at the downstream level. In order to understand the immediate physio-metabolic effects of face masks, we need to monitor continuous changes in metabolic markers along with simultaneous changes in respiratory and haemodynamic parameters.

In this context, high-resolution mass-spectrometry based real-time analysis of exhaled volatile organic compounds (VOCs) could offer a unique insight into body's immediate physiological[13-17] and metabolic[18, 19] status. Continuous and breath-resolved measurements allow us to track changes in exhaled metabolic markers over the durations of mask use. Combining VOC profiling with simultaneous pulseoximetry, capnography and haemodynamic monitoring could enable an unconventional understanding of clinically relevant effects of face masks.

We applied online high-resolution mass-spectrometry (i.e. proton transfer reaction - time-of-flight - mass-spectrometry / PTR-ToF-MS) based breathomics in parallel to non-invasive measurements of $\mathrm{SpO}_{2}$, respiratory rate, $\mathrm{pET}-\mathrm{CO}_{2}$, exhaled humidity and oxygen, cardiac output, stroke volume, heart rate and blood pressure etc. The physio-metabolic side effects of FFP2 and surgical masks over 15-30 
min of use on healthy human subjects aged between 20-80 years will be addressed in detail. Effects from both masks will be compared upon wearing duration and age in order to realize any further needs for reforming the present global-pandemic policies.

\section{Methods}

\section{Human subjects:}

All experiments were conducted according to the amended Declaration of Helsinki guidelines and signed informed consent from 30 subjects (aged between 20 - 80 years) were obtained (Approval number: A2021-0012 - issued by the Institutional Ethics Committee of University Medicine Rostock, Germany) prior to inclusion. Subjects were not suffering from any acute diseases/health condition and were not undertaking any special diet and/or medication. Among the subjects above the age of 60, three had mild COPD (one male and two female) and two had chronic bronchitis (female) in the past.

\section{Determination of sample size:}

We applied the analysis of variance (ANOVA) test for calculation of sample size. For a minimum detectable difference in mean substance intensities of $450 \mathrm{cps}$, a standard deviation of 300 was estimated. To attain an alpha value of 0.005 and a test power of 0.99 experimental groups, while considering a population of 100,000 , the sample size resulted at 26 (with minimal group size of at least 13 each). In this study, we have included 30 subjects for analysis in order to detect even less than $5 \%$ differences in exhaled VOCs up to low parts per trillion by volume (pptV) levels.

Table 1: Anthropometric information of subjects.

\begin{tabular}{|c|c|c|c|c|c|c|c|c|c|c|}
\hline & \multicolumn{4}{|c|}{ Demographic Data } & \multicolumn{6}{|c|}{ Lifestyle Habits / Life Events } \\
\hline $\begin{array}{l}\text { Participant } \\
\text { groups }\end{array}$ & Gender & Number & $\begin{array}{c}\text { Age } \\
\text { range } \\
\text { (Years) }\end{array}$ & $\begin{array}{c}\text { BMI } \\
\text { range } \\
\text { (Kg/sq.m) }\end{array}$ & Smoker & Alcoholic & $\begin{array}{l}\text { Special } \\
\text { diet }\end{array}$ & $\begin{array}{c}\text { Acute, } \\
\text { Chronic } \\
\text { Disease / } \\
\text { Medication }\end{array}$ & Contraception & $\begin{array}{c}\text { Pregnancy/ } \\
\text { Expecting }\end{array}$ \\
\hline \multirow[t]{2}{*}{ Adults } & $\mathrm{M}$ & 8 & 20 to 59 & $(18-25)$ & $\begin{array}{c}\text { Yes } \\
(\mathrm{n}=01)\end{array}$ & No & No & No & $\mathrm{N} / \mathrm{A}$ & $\mathrm{N} / \mathrm{A}$ \\
\hline & $\mathrm{F}$ & 9 & 20 to 59 & $(19-29)$ & $\begin{array}{c}\text { Yes } \\
(n=03)\end{array}$ & No & No & No & No & No \\
\hline \multirow[t]{2}{*}{ Elderly } & M & 7 & 60 to 80 & $(21-27)$ & $\begin{array}{c}\text { Yes } \\
(\mathrm{n}=02)\end{array}$ & No & No & $\begin{array}{c}\text { Mild COPD (n } \\
=1 \text { ) } \\
\text { Chronic } \\
\text { Bronchitis } \\
(\mathrm{n}=2)\end{array}$ & $\mathrm{N} / \mathrm{A}$ & $\mathrm{N} / \mathrm{A}$ \\
\hline & F & 6 & 60 to 80 & $(23-29)$ & $\begin{array}{c}\text { Yes } \\
(\mathrm{n}=02)\end{array}$ & No & No & $\begin{array}{c}\text { Mild COPD (n } \\
=2)\end{array}$ & $\mathrm{N} / \mathrm{A}$ & $\mathrm{N} / \mathrm{A}$ \\
\hline
\end{tabular}

Number of subjects in each group, age range and body mass index (BMI) range are listed along with life style attributes e.g. cigarette smoking or alcohol drinking or any special dietary habits and clinically important parameters e.g. any health condition or medication etc.

\section{Assignment of groups:}

We have divided the study population in two groups; namely: adults ( $<60$ years of age) and elderly ( $>60$ years of age). Anthropometric data were confirmed by participants during inclusion and are presented in Table 1. 


\section{Experimental setup:}

Three devices were synchronized for real-time measurements of several parameters simultaneously (Fig. 1). Continuous monitoring of breath VOCs, exhaled abundances of $\mathrm{O}_{2}, \mathrm{CO}_{2}$ and humidity via PTR-ToF-MS, non-invasive measurements of haemodynamic parameters via volume clamp method, $\mathrm{SpO}_{2}$ monitoring via pulseoximetry. Main-stream capnography (for $\mathrm{pET}$ - $\mathrm{CO}_{2}$ ) was performed immediately before and after the mask use. Data acquisition was initiated in parallel.

\section{Breath sampling protocol:}

Volunteers rested by sitting on a chair for at least 10 min before actual sampling. Each participant were instructed to maintained the sitting posture[20] and then wore a face mask to breathe orally. They spontaneously inhaled and exhaled only via mouth[21].

The transfer-line of PTR-ToF-MS was connected (via PEEK finger-tight fittings) to a PEEK extension line (i.e. $30 \mathrm{~cm}$ long, with outer diameter of $1 \mathrm{~mm}$ and inner diameter of $0.75 \mathrm{~mm}$ ) in order to directly sample breath-resolved VOCs from the mask dead space (Fig. 1). The PTR transfer line was fixed (via metal clamps) at the back of subject's head (at a level below the left/right earlobe). The PEEK line was placed along the subject's right/left cheek (following the maxillary line) and was inserted within the mask dead space till the front of subject's lips. The tip of this sampling line was cased within a conical PEEK ferrule in order to avoid any unwanted contact with mask surface or with subject's lips. These extension lines were sterilized for reuse.

In each volunteer, measurements with two different masks (viz. FFP2 and surgical) were conducted on two consecutive days and at the same time. Adults were measured for $30 \mathrm{~min}$ and elderly subjects were measured for $15 \mathrm{~min}$. The measurements in elderly subjects were stopped once they attained a $\mathrm{SpO}_{2}$ level $<94 \%$.

\section{PTR-ToF-MS measurements of breath VOCs:}

Breath VOCs were measured continuously via a PTR-ToF-MS 8000 (Ionicon Analytik GmbH, Innsbruck, Austria) and with pre-optimized experimental conditions $[15,22]$, i.e. continuous side-stream mode of sampling via a $6 \mathrm{~m}$ long heated $\left(\mathrm{at} 75^{\circ} \mathrm{C}\right)$ silico-steel transfer-line connected to a sterile mouthpiece. A continuous sampling flow of $20 \mathrm{ml} / \mathrm{min}$ was applied and the time resolution of the PTR-ToF-MS measurements was $200 \mathrm{~ms}$. Thus, data points were generated after every $200 \mathrm{~ms}$ and on each data point hundreds of compounds were measured at their trace abundances (in both expiratory- and room air). The ion source current was set to $4 \mathrm{~mA}$ and the $\mathrm{H}_{2} \mathrm{O}$ flow was set to $6 \mathrm{ml} / \mathrm{min}$. Drift tube temperature was set to $75^{\circ} \mathrm{C}$, voltage was $610 \mathrm{~V}$ and the pressure was $2.3 \mathrm{mbar}$. The resulting E/N ratio was $139 \mathrm{Td}$. After every minute a new data file was recorded automatically and the mass scale was recalibrated after each run (60 s). We used the following masses for mass calibration: $21.0226\left(\mathrm{H}_{3} \mathrm{O}^{+}\right.$-Isotope), $29.9980\left(\mathrm{NO}^{+}\right)$and $59.049\left(\mathrm{C}_{3} \mathrm{H}_{6} \mathrm{O}\right)$.

\section{VOC data processing:}

VOCs were measured in counts per seconds (cps) and corresponding intensities were normalised onto primary ion $\left(\mathrm{H}_{3} \mathrm{O}^{+}\right)$counts. Raw data was processed via PTR-MS viewer software (version 3.4). As PTR-MS continuously records both exhaled breath and inhaled room-air, the 'breath tracker' algorithm (based on Matlab version 7.12.0.635, R2011a) was applied to identify expiratory and inspiratory phases[15]. Here, acetone was used as the tracker mass as it is an endogenous substance, which has significantly higher signal intensity in expiration than in inhalation. As the high mass resolution of PTR-ToF-MS $(4000-5000 \Delta \mathrm{m} / \mathrm{m})$ can assign volatiles upon their measured mass and corresponding sum formula with high precision[21], compound names are used while discussing results. VOCs were quantified via multi-component mixture of standard reference substances. Quantification process under adapted sample humidity (as in exhaled breath) using a liquid calibration unit (LCU, Ionicon Analytik GmbH, Innsbruck, Austria) is our pre-established state-of-the-art[23].

\section{Selection of VOCs for analysis:}

Here we considered compounds with expiratory abundances significantly above the inspiratory/room-air abundance. Out of those markers 32 substances were selected. These VOCs are well-known breath markers in clinical breathomics and reflect different origins, 
physicochemical characters and dependencies on physiology, metabolism, pathology, therapy and lifestyle/habits[18, 19, 21, 24, 25]. None of these VOCs were contributed from the applied masks as we examined the mask emissions for direct comparisons.

\section{Continuous haemodynamic monitoring.}

Non-invasive measurements of haemodynamic parameters (e.g. cardiac output, stroke volume, pulse rate and mean arterial pressure etc.) were performed via our pre-optimised setup by using volume clamp method (ClearSight system-EV1000, Edwards Lifesciences, California, USA)[14, 20].

\section{Mainstream capnography:}

Main stream capnography was performed just before and after each mask use via a small portable capnograph (EMMA ${ }^{\mathrm{TM}}$ PN 3639 , Ref: 605102, Masimo â Sweden AB, Danderyd, Sweden) attached to a sterile breathing mouthpiece. $\mathrm{pET}-\mathrm{CO}_{2}$ values were recorded in $\mathrm{mmHg}$ unit. Absolute values are considered from the $3^{\text {rd }}$ breath onward as first two to three breaths are used to calibrate the $\mathrm{CO}_{2}$ and RR sensor.

\section{Statistical analysis:}

Analytical mean values (of measured parameters) from each participant were calculated over each minute of breath-resolved measurement. Data from every $5^{\text {th }}$ minute were included for statistical analysis. In case of any non-parametric distribution of data, median values were considered for statistical analysis.

In order to reduce the evident intra-individual variations in measured variables, each participant was used as his/her own control. Thus, variables from each subject were normalised onto the corresponding initial values (of the first minute). Normalisation was performed separately for each mask types (FFP2 and surgical) and in each age groups (adults and elderly).

As every group mean/median value are contributed by each volunteer (of that group), the relative standard deviations (RSDs) in VOC abundances from each group were also calculated for each substance. The RSDs were calculated (in \%) by rating sample standard deviations (SDs) over corresponding sample means.

Statistically significant differences within groups were assessed via repeated measurement ANOVA on ranks (Friedman repeated measures analysis of variance on ranks, Shapiro-Wilk test for normal distribution and post hoc Student-Newman-Keuls method for pairwise multiple comparisons between all groups; $p$-value $\leq 0.005)$ in SigmaPlot software (version 14).

For all measured variables, from all pairwise comparisons, the differences are presented by referring to the corresponding values at the $1^{\text {st }}$ minute of each mask and within each age group.

In order to compare the effects of both mask types on both age groups, relative changes (in \%) over time (with respect to initial values) were calculated for selected variables. Here, we have selected the principal physio-metabolic denominators and candidate VOCs that are potentially originating from several in vivo metabolic processes. Relative changes were calculated at $15^{\text {th }}$ and $30^{\text {th }}$ min in adults and at $15^{\text {th }} \mathrm{min}$ in elderly cohort. The changes in $\mathrm{PET}-\mathrm{CO}_{2}$ values were calculated between immediately before and after mask use. In case of inter-group comparisons, one-way ANOVA was applied due to unequal group size. All groups were compared to each other.

In order to understand the correlations between exhaled VOCs and physiological parameters within each mask type, dimension reduction factor analysis (Factor extraction via principal components method, factor scores via regression method and 1-tailed significance at $p$-value $\leq 0.005$ ) were performed in SPSS.

\section{Results}

Figure 2 represents heatmaps of relative changes in normalised mean values of physiological parameters such as, partial pressure of the end-tidal $\mathrm{CO}_{2}\left(\mathrm{pET}-\mathrm{CO}_{2}\right)$, peripheral oxygen saturation $\left(\mathrm{SpO}_{2}\right)$, respiratory rate (RR), cardiac output (CO), stroke volume (SV), pulse rate (PR), mean arterial pressure (MAP) and relative changes in exhaled alveolar abundances of 32 protonated/charged VOCs of 
interest during the use of FFP2 and surgical face masks by healthy adults and elderly cohorts. VOC selection criteria is described in method section. Measured variables from each volunteer were normalised onto corresponding median values from the first minute. The mean of those normalised values from every $5^{\text {th }}$ minute is presented in the heatmaps. $\mathrm{PET}-\mathrm{CO}_{2}$ values are depicted from immediately before and after the mask use and are placed at the first and final minute of heatmaps for direct comparisons. The changes in relative standard deviations (RSDs) of all measured parameters are presented via heatmaps in Supplementary Figure-S1.

Figure 3 (Boxplots) is depicting absolute or normalised values of physiological parameters and of alveolar concentrations of exhaled VOCs in every $5^{\text {th }}$ minute (starting from the $1^{\text {st }} \mathrm{min}$ ) in four groups. First two groups consist of data from FFP2 masks on adults and elderly cohorts, respectively. Later two groups contain data from surgical masks on adults and elderly cohorts, respectively. $\mathrm{pET}^{\mathrm{C}} \mathrm{CO}_{2}$ values are presented from immediately before and after the use of masks. Here, 3 (A) represents the physiological parameters viz. absolute values of $\mathrm{SpO}_{2}, \mathrm{pET}-\mathrm{CO}_{2}$ and respiratory rate and normalised values of haemodynamics. 3 (B) represents aliphatic aldehydes and organosulfur, 3 (C) represents hemiterpene, ketone and smoking/environment related VOCs, exhaled humidity and oxygen, 3 (D) represents aliphatic acids, alcohols and monoterpene. Absolute values are only considered for parameters, which are less likely to be affected by inter- or intra-day variations within each individual. From all pairwise comparisons, the differential expressions (viz. statistically significant at $p$-value $\leq 0.005)$ in each variable within each group is indicated with respect to the corresponding ' $1^{\text {st }}$ minute' of measurement.

The correlation coefficients and respective $p$-values between physiological parameters and VOCs of interest are presented in Table 2. Detailed inter-VOC correlations (with respect to physiological parameters) along with corresponding $p$-values are presented in Supplementary Table-S1 and S2.

Figure 4 (Boxplots) is depicting comparison of relative changes (in \%) in physiological parameters and in selected metabolic breath markers within four groups. First two groups are of FFP2 masks on adults and elderly cohorts, respectively and later two groups are of surgical masks on adults and elderly cohorts, respectively. Relative changes (with respect to initial values) in adults at the $15^{\text {th }}$ and $30^{\text {th }} \mathrm{min}$ and in elderly cohort at the $15^{\text {th }} \mathrm{min}$ is presented. For $\mathrm{pET}-\mathrm{CO}_{2}$, relative changes between measured values immediately before and after use of masks are presented. Here, 4 (A) represents physio-metabolic parameters and 4 (B) represents exhaled alveolar volatile organic metabolites. From all pairwise-multiple comparisons, differences (with corresponding $p$-values) in all variables between groups are indicated with respect to the ' $15^{\text {th }}$ minute in elderly with FFP2 mask' in Table 3.

Table 2: Correlation (obtained via factor analysis) between physiological parameters and selected VOCs of interest.

\begin{tabular}{|c|c|c|c|c|c|c|c|c|c|c|c|c|c|}
\hline & \multicolumn{6}{|c|}{ FFP2 mask } & & \multicolumn{6}{|c|}{ Surgical mask } \\
\hline & $\mathrm{CO}$ & $S V$ & $P R$ & $M A P$ & $R R$ & $\mathrm{SpO}_{2}$ & & $\mathrm{CO}$ & $S V$ & $P R$ & MAP & $R R$ & $\mathrm{SpO}_{2}$ \\
\hline \multirow[t]{2}{*}{ Isoprene } & 0.11 & -0.15 & 0.33 & -0.02 & 0.38 & 0.18 & $R$ value & -0.39 & -0.39 & 0.14 & -0.34 & -0.23 & 0.08 \\
\hline & 0.099 & 0.037 & 0.000 & 0.395 & 0.001 & 0.018 & $p$-value & 0.000 & 0.000 & 0.064 & 0.000 & 0.006 & 0.184 \\
\hline \multirow[t]{2}{*}{ Acetone } & 0.03 & -0.25 & 0.31 & 0.12 & 0.27 & 0.10 & $R$ value & -0.28 & -0.3 & 0.1 & -0.46 & -0.04 & -0.09 \\
\hline & 0.380 & 0.002 & 0.000 & 0.085 & 0.001 & 0.126 & $p$-value & 0.001 & 0.000 & 0.139 & 0.000 & 0.337 & 0.172 \\
\hline \multirow[t]{2}{*}{ Acetaldehyde } & 0.05 & -0.14 & 0.28 & -0.25 & -0.20 & -0.05 & $R$ value & -0.16 & -0.11 & 0.03 & 0.19 & 0.02 & 0.07 \\
\hline & 0.288 & 0.047 & 0.000 & 0.002 & 0.009 & 0.268 & $p$-value & 0.044 & 0.111 & 0.373 & 0.020 & 0.395 & 0.212 \\
\hline \multirow[t]{2}{*}{ Butyraldehyde } & -0.04 & -0.15 & 0.15 & -0.15 & -0.10 & -0.01 & $R$ value & -0.24 & -0.23 & 0.16 & 0.2 & -0.05 & 0.13 \\
\hline & 0.312 & 0.037 & 0.042 & 0.045 & 0.115 & 0.461 & p-value & 0.005 & 0.005 & 0.045 & 0.016 & 0.288 & 0.078 \\
\hline \multirow[t]{2}{*}{ Dimethyl sulfide } & 0.17 & -0.14 & 0.38 & -0.03 & 0.33 & 0.15 & $R$ value & -0.29 & -0.34 & 0.16 & -0.38 & -0.25 & 0.07 \\
\hline & 0.027 & 0.051 & 0.000 & 0.373 & 0.000 & 0.043 & $p$-value & 0.001 & 0.000 & 0.045 & 0.000 & 0.003 & 0.229 \\
\hline \multirow[t]{2}{*}{ Butanethiol } & -0.10 & -0.13 & 0.07 & -0.02 & -0.13 & 0.33 & $R$ value & -0.32 & -0.11 & -0.23 & -0.26 & -0.05 & 0.14 \\
\hline & 0.116 & 0.059 & 0.222 & 0.409 & 0.072 & 0.000 & $p$-value & 0.000 & 0.108 & 0.006 & 0.002 & 0.279 & 0.059 \\
\hline \multirow[t]{2}{*}{ Acetic acid } & -0.14 & -0.03 & -0.15 & -0.02 & 0.08 & 0.41 & $R$ value & -0.16 & -0.09 & -0.09 & -0.13 & -0.2 & 0.2 \\
\hline & 0.051 & 0.355 & 0.039 & 0.390 & 0.190 & 0.000 & $p$-value & 0.041 & 0.171 & 0.162 & 0.074 & 0.016 & 0.015 \\
\hline \multirow[t]{2}{*}{ Butyric acid } & 0.11 & 0.01 & 0.14 & 0.02 & 0.12 & 0.20 & $R$ value & -0.14 & -0.09 & -0.07 & -0.15 & -0.31 & 0.12 \\
\hline & 0.093 & 0.437 & 0.055 & 0.393 & 0.090 & 0.009 & $p$-value & 0.068 & 0.177 & 0.217 & 0.053 & 0.000 & 0.101 \\
\hline \multirow[t]{2}{*}{ Ethanol } & 0.082 & -0.18 & 0.35 & -0.17 & -0.11 & -0.04 & $R$ value & -0.3 & -0.27 & 0.09 & 0.05 & 0.03 & -0.08 \\
\hline & 0.171 & 0.019 & 0.000 & 0.023 & 0.107 & 0.313 & $p$-value & 0.000 & 0.002 & 0.166 & 0.298 & 0.375 & 0.204 \\
\hline \multirow[t]{2}{*}{ Limonene } & -0.04 & -0.21 & 0.20 & 0.15 & 0.41 & 0.00 & $R$ value & -0.2 & -0.16 & -0.02 & -0.46 & -0.01 & -0.21 \\
\hline & 0.326 & 0.007 & 0.011 & 0.045 & 0.000 & 0.488 & $p$-value & 0.013 & 0.043 & 0.411 & 0.000 & 0.465 & 0.011 \\
\hline \multirow[t]{2}{*}{ Furan } & 0.09 & -0.20 & 0.38 & -0.03 & 0.27 & 0.13 & $R$ value & -0.4 & -0.4 & 0.16 & -0.28 & -0.27 & 0.06 \\
\hline & 0.139 & 0.009 & 0.000 & 0.381 & 0.001 & 0.067 & $p$-value & 0.000 & 0.000 & 0.044 & 0.001 & 0.001 & 0.245 \\
\hline \multirow[t]{2}{*}{ Exhaled $\mathrm{O}_{2}$} & 0.10 & -0.22 & 0.33 & 0.12 & 0.09 & 0.08 & $R$ value & -0.62 & -0.83 & 0.59 & -0.62 & -0.13 & 0.11 \\
\hline & 0.132 & 0.005 & 0.000 & 0.089 & 0.145 & 0.173 & $p$-value & 0.000 & 0.000 & 0.000 & 0.000 & 0.083 & 0.127 \\
\hline \multirow[t]{2}{*}{ Exhaled $\mathrm{H}_{2} \mathrm{O}$} & -0.01 & -0.15 & 0.13 & 0.31 & 0.28 & -0.17 & $R$ value & -0.11 & -0.21 & 0.19 & -0.02 & -0.25 & -0.29 \\
\hline & 0.448 & 0.041 & 0.065 & 0.000 & 0.000 & 0.023 & $p$-value & 0.122 & 0.010 & 0.021 & 0.428 & 0.003 & 0.001 \\
\hline
\end{tabular}


Correlation coefficients ( $\mathrm{R}$ value) along with corresponding $p$-values are listed. Statistically significant ( $p$-value $\leq 0.005)$ correlations are assigned in bold. The values '0.000' denominates $p$-values $<0.001$.

Table 3: Results from pairwise-multiple comparisons of relative changes (in \%) between groups.

\begin{tabular}{|l|c|c|c|}
\hline $\mathrm{SpO}_{2}$ & Vs. & P-value & Sig. \\
\hline FFP2_15min_E & FFP2_15min_A & $<0.001$ & Yes \\
& FFP2_30min_A & $<0.001$ & Yes \\
& Surg_15min_A & $<0.001$ & Yes \\
& Surg_30min_A & $<0.001$ & Yes \\
\cline { 2 - 4 } & Surg_15min_E & $<0.001$ & Yes \\
\hline RR & Vs. & P-value & Sig. \\
\hline FFP2_15min_EE & FFP2_15min_A & $<0.001$ & Yes \\
& FFP2_30min_A & $\mathbf{0 . 0 0 3}$ & Yes \\
& Surg_15min_A & 0.212 & No \\
\cline { 2 - 3 } & Surg_30min_A & 0.149 & No \\
\cline { 2 - 3 } & Surg_15min_E & 0.365 & No \\
\hline
\end{tabular}

\begin{tabular}{|l|c|r|l|}
\hline CO & Vs. & P-value & Sig. \\
\hline FFP2_15min_EE & FFP2_15min_A & $\mathbf{0 . 0 0 2}$ & Yes \\
& FFP2_30min_A & 0.35 & No \\
& Surg_15min_A & $\mathbf{0 . 0 0 4}$ & Yes \\
& Surg_30min_A & 1.471 & No \\
\cline { 2 - 4 } & Surg_15min_E & $\mathbf{0 . 0 0 5}$ & Yes \\
\hline
\end{tabular}

\begin{tabular}{|c|c|c|c|}
\hline pET-CO2 & Vs. & P-value & Sig. \\
\hline \multirow[t]{3}{*}{ FFP2_15min_E } & Surg_30min_A & $<0.001$ & Yes \\
\hline & FFP2_30min_A & $<0.001$ & Yes \\
\hline & Surg_15min_E & $<0.001$ & Yes \\
\hline
\end{tabular}

\begin{tabular}{|l|c|c|l|}
\hline Exhaled $\mathrm{O}_{2}$ & Vs. & P-value & Sig. \\
\hline FFP2_15min_EE & FFP2_15min_A & $<0.001$ & Yes \\
& FFP2_30min_A & 0.266 & No \\
& Surg_15min_A & $\mathbf{0 . 0 0 2}$ & Yes \\
& Surg_30min_A & $<0.001$ & Yes \\
\cline { 2 - 4 } & Surg_15min_E & 1.567 & No \\
\hline
\end{tabular}

\begin{tabular}{|l|c|r|l|}
\hline MAP & Vs. & P-value & Sig. \\
\hline FFP2_15min_E & FFP2_15min_A & $\mathbf{0 . 0 0 3}$ & Yes \\
& FFP2_30min_A & 1.25 & No \\
\cline { 2 - 4 } & Surg_15min_A & $\mathbf{0 . 0 0 5}$ & Yes \\
\cline { 2 - 4 } & Surg_30min_A & 0.007 & No \\
\cline { 2 - 4 } & Surg_15min_E & $\mathbf{0 . 0 0 1}$ & Yes \\
\hline
\end{tabular}

\begin{tabular}{|l|c|r|l|}
\hline Isoprene & Vs. & P-value & Sig. \\
\hline FFP2_15min_E & FFP2_15min_A & $<0.001$ & Yes \\
& FFP2_30min_A & $\mathbf{0 . 0 0 2}$ & Yes \\
\cline { 2 - 4 } & Surg_15min_A & 1.453 & No \\
\cline { 2 - 4 } & Surg_30min_A & $\mathbf{0 . 0 0 5}$ & Yes \\
\cline { 2 - 4 } & Surg_15min_E & $\mathbf{0 . 0 0 1}$ & Yes \\
\hline
\end{tabular}

\begin{tabular}{|l|c|r|l|}
\hline Exhaled $\mathrm{H}_{2} \mathrm{O}$ & Vs. & P-value & Sig. \\
\hline FFP2_15min_E & FFP2_15min_A & $<0.001$ & Yes \\
& FFP2_30min_A & 0.37 & No \\
& Surg_15min_A & $<\mathbf{0 . 0 0 1}$ & Yes \\
& Surg_30min_A & $\mathbf{0 . 0 0 5}$ & Yes \\
\cline { 2 - 4 } & Surg_15min_E & $\mathbf{0 . 0 0 1}$ & Yes \\
\hline
\end{tabular}

\begin{tabular}{|l|c|r|l|}
\hline Acetone & Vs. & P-value & Sig. \\
\hline FFP2_15min_E & FFP2_15min_A & 0.063 & No \\
& FFP2_30min_A & $<0.001$ & Yes \\
\cline { 2 - 3 } & Surg_15min_A & 1.055 & No \\
\cline { 2 - 3 } & Surg_30min_A & $<0.001$ & Yes \\
\cline { 2 - 3 } & Surg_15min_E & 1.121 & No \\
\hline
\end{tabular}

\begin{tabular}{|l|l|r|l|}
\hline DMS & Vs. & P-value & Sig. \\
\hline FFP2_15min_EE & FFP2_15min_A & $\mathbf{0 . 0 0 3}$ & Yes \\
& FFP2_30min_A & $<0.001$ & Yes \\
\cline { 2 - 4 } & Surg_15min_A & 0.75 & No \\
\cline { 2 - 4 } & Surg_30min_A & $\mathbf{0 . 0 0 4}$ & Yes \\
\cline { 2 - 4 } & Surg_15min_E & 0.368 & No \\
\hline
\end{tabular}

\begin{tabular}{|l|c|r|l|}
\hline Acetic acid & Vs. & P-value & Sig. \\
\hline FFP2_15min_E & FFP2_15min_A & 2.003 & No \\
& FFP2_30min_A & 1.301 & No \\
& Surg_15min_A & $\mathbf{0 . 0 0 1}$ & Yes \\
& FFP2_30min_A & $<\mathbf{0 . 0 0 1}$ & Yes \\
\cline { 2 - 4 } & Surg_15min_E & 0.554 & No \\
\hline
\end{tabular}

\begin{tabular}{|l|c|r|l|}
\hline Acetaldehyde & Vs. & P-value & Sig. \\
\hline FFP2_15min_EE & FFP2_15min_A & 1.81 & No \\
& FFP2_30min_A & 2.065 & No \\
& Surg_15min_A & 0.05 & No \\
\cline { 2 - 4 } & Surg_30min_A & 0.021 & No \\
\cline { 2 - 4 } & Surg_15min_E & $\mathbf{0 . 0 0 1}$ & Yes \\
\hline
\end{tabular}

\begin{tabular}{|l|c|r|l|}
\hline Limonene & Vs. & P-value & Sig. \\
\hline FFP2_15min_E & FFP2_15min_A & $<0.001$ & Yes \\
& FFP2_30min_A & $\mathbf{0 . 0 0 5}$ & Yes \\
& Surg_15min_A & $\mathbf{0 . 0 0 4}$ & Yes \\
& Surg_30min_A & $\mathbf{0 . 0 0 1}$ & Yes \\
& Surg_15min_E & 1.331 & No \\
\hline
\end{tabular}

\begin{tabular}{|l|c|r|l|}
\hline Ethanol & Vs. & P-value & Sig. \\
\hline FFP2_15min_E & FFP2_15min_A & 0.006 & No \\
& FFP2_30min_A & $\mathbf{0 . 0 0 1}$ & Yes \\
& Surg_15min_A & 0.031 & No \\
& Surg_30min_A & 0.4 & No \\
\cline { 2 - 3 } & Surg_15min_E & $\mathbf{0 . 0 0 3}$ & Yes \\
\hline
\end{tabular}

Statistical significances are tested by means of repeated measurement-ANOVA on ranks ( $p$-value $\leq 0.005$ ). From all pairwise-multiple comparisons, statistically significant difference along with corresponding $p$-values are listed with respect to \% of changes caused by "FFP2 mask on elderly (FFP2_15min_E) cohort". Statistically significant ( $p$-value $\leq 0.005$ ) correlations are assigned in bold.

\section{Discussion}


FFP2 and surgical face-masks immediately affected physiological and metabolic attributes. Effects were progressed with the course of mask wearing time. Most pronounced effects were observed in case of FFP2 mask and especially in elderly subjects. Profound and consistent decrease in $\mathrm{SpO}_{2}$ and increase in $\mathrm{pET}-\mathrm{CO}_{2}$ have indicated ascending deoxygenation[26] and deteriorating ventilation in all subjects, which are caused mainly due to rebreathing of $\mathrm{CO}_{2}[27,28]$ from mask dead space and change in normal breathing patterns. Haemodynamic parameters such as cardiac output and MAP changed in counter-(homeostatic)-response/secondary to those respiratory effects. Irrespective of the origins, significant and substance-specific changes in exhalation of many blood-borne volatile metabolites took place within minutes. Some changes mirrored the profiles of oxygen saturation, haemodynamics and respiratory parameters. Exhaled oxygen decreased while breath humidity increased over time. Exhalation profiles of potentially endogenous aldehydes, hemiterpene, organosulfur, alcohols, ketones and short-chain fatty acids have indicated in vivo physio-metabolic cross-talks between hypoxia and oxidative stress, hypoventilation and compartmental vasoconstriction, altered systemic bacterial activity and energy homeostasis etc. Exhalation of exogenous aromatics, nitriles and monoterpenes were mainly related to pre-exposers and lifestyle.

While looking at the $\mathrm{CO}_{2}$ exhalation and accumulation of breath humidity over time, a systematic effect of rebreathing to increase most of the VOCs (with high aqueous solubility or high volatility) could be assumed. Nevertheless, endogenous VOCs with similar physiochemical properties behaved in contrast by clearly indicating more systemic effects on their putative in vivo/metabolic origins.

Hypoxia and deoxygenation facilitates the production of reactive oxygen species (ROS) and thereby promotes acute oxidative stress $[29,30]$. This further leads to lipid peroxidation and production of $a, \beta$-unsaturated aldehydes[31]. In our setup, the instant and gradual increase in endogenous acetaldehyde, butyraldehyde and pentanaldehyde exhalations along with the decreasing $\mathrm{SpO}_{2}$ in case of FFP2 masks indicates an early onset and progression of oxidative stress. Such oxidative stress was insignificant in case of surgical masks, even in elderly subjects. As oxidative stress driven disbalance in $\mathrm{O}_{2}$ and ROS interplay may lead to acute cardiac dysfunction[32], DNA damage[33], oncogene activation and cancers[34] etc. the selection of face-mask should be re-evaluated. Crotonaldehyde is formed via condensation of acetaldehyde molecules in alkaline medium and thereby cannot be attributed directly to oxidative stress. Acrolein behaved differently due to its exogenous origin from diet, smoking and/or environment[35].

While looking at the exhalation profiles of organosulfur such as DMS, AMS and butanethiol, the effects of both face-masks are reflected on the systemic origin of these substances from microbial anaerobic methylation[36] in the lower gut. Studies have shown that effects of hypoxia acts as an 'invisible pusher' of gut microbiota[37]. Gut flora maintain the hypoxic balance of the intestinal environment in order to regulate the nutrient absorption, gut permeability and immune response[38]. As face-mask externally induces a deoxygenation, the normal gut microbial activity is likely to reduce gradually, resulting in descending production of those organosulfur in colon region. Despite an increase in cardiac output, exhaled abundances of these substances decreased significantly in case of both masks in either age groups. This could be due to the fact that the perfusion was distributed to active compartments (tissue/organs) with increased $\mathrm{O}_{2}$ demand rather than in the gut. Due to its origin from the oral cavity bacteria[21], no systemic effects were observed in the exhalation of $\mathrm{H}_{2} \mathrm{~S}$.

Short-chain fatty acids (SCFAs) e.g. acetic acid and butyric acid are produced by lower gut bacteria during the anaerobic lysis of primarily undigested dietary fibres and/or starch $[39,40]$. Due to their origin from large-intestinal environment, exhaled profiles behaved as the gut originated sulphides. Further to that SCFAs plays important role in energy metabolism, plasma acid-base homeostasis and blood pressure regulation[41, 42]. As prolonged hypoxia eventually may leads to anaerobiosis and metabolic acidosis (lowering of plasma $p \mathrm{H}$ )[43], SCFAs production is very likely to be reduced. Crotonic acid and formic acid are potentially sourced from cosmetics and disinfectant/sanitizers and similar to our previous observations[14, 44], those VOCs reflected washout behaviours.

Despite its origin from carbohydrate metabolizing bacteria of the intestine[45, 46], ethanol did not follow the behaviours of organosulfur or SCFAs. In contrast, ethanol exhalations tend to increase and rose most significantly in elderly cohort with FFP2 mask by mirroring the profiles of cardiac output and MAP. Evidences have indicated hypoxic switching of metabolic routes that produce more ethanol than lactates in order to regulate blood $p \mathrm{H}$ levels[43]. Endogenous ethanol increases the permeability of small-intestinal epithelium and colon in order to increase glucose transport towards hepatic and cellular glycolysis[47]. A consecutives descent in endogenous breath acetone (i.e. the by-product of glycolysis)[48] indicate a decline in carbohydrate metabolism and a demand in glucose uptake for energy metabolism. An elevated MAP and -cardiac output denominate increased perfusion[49] of vital organs to aid the primary source of energy from the compartments such as the small-intestine. Therefore, the increase in ethanol exhalation may be due to its signalling act[50] between intestinal permeability and glucose transport to blood for maintaining the energy homeostasis. 
The observed tendencies of various gut-originated VOCs reflect the regional diversity of systemic microflora within same organ. Phenol and isopropanol behaved differently than ethanol due to their exogenous origin from the dietary intake, beverages and uptake from the ambient environment, disinfectants or sanitizers.

During spontaneous breathing in normal sitting position, exhalation of $\mathrm{CO}_{2}$ and endogenous isoprene[51] exhalation remain closely related to each other and they positively mirror cardiac output and negatively mirror ventilation[14, 20]. Pronounced increase in $p E T-$ $\mathrm{CO}_{2}$ values from before to after use of both masks occurred most likely due to partial rebreathing from the mask dead space and changes in spontaneous respiration (e.g. changes in inspiratory/expiratory time) that may alter alveolar slope[52]. Those effects are expected to elevate breath isoprene as was observed during exhalation of expiratory reserve volume by healthy subjects[14]. Within this setup, isoprene exhalation remained independent of cardiac output and $\mathrm{CO}_{2}$ exhalation. Previously we have observed that breath holding manoeuvres[15,53] and externally applied upper-airway resistances against respiratory flow[44] had significantly increased breath isoprene concentrations. Although respiratory rate tends to decrease in adults and increase in elderly subjects, the changes remained within the normal physiological range. In all cases, isoprene concentrations significantly decreased throughout the experiments; most likely due to the sympathetic vasoconstriction (deoxygenation induced) in muscle compartments[54], which are the potential storage of this VOC but stayed inactive while sitting. Previously, we witnessed such decline in breath isoprene (in contrast to cardiac output) in healthy adults during the second minute in standing posture[20]. At that point, cardiac output started to increase but isoprene still decreased as sympatho-adrenergic vasoconstrictions took place in the lower extremities of the body to push up (against gravitation) the peripheral blood volume towards thoracic compartments. This was in order to counter the falling blood pressure and cardiac output while standing. As distribution of blood flow is crucial under hypoxia[55], in the present setup, the same phenomena might have helped to redistribute the available perfusion within active compartments in order to aid the rising $\mathrm{O}_{2}$ demand. Due to having both haemoglobin and plasma bicarbonate buffer, such effects were not observed in case of $\mathrm{pET}-\mathrm{CO}_{2}$. Surprisingly, we have observed hyperventilation ( $\mathrm{pET}-\mathrm{CO}_{2}<35 \mathrm{mmHg}$ ) in most of the elderly subjects even before wearing the masks for our experiment. This could occur in order to compensate/eliminate the elevated $\mathrm{pET}-\mathrm{CO}_{2}$ from precedent mask wearing (while arriving from elsewhere to our setup) phase. Although we let all subjects sit without any mask for $15 \mathrm{~min}$ within our setup before starting experiments, this seem to be not enough to compensate the precedent effects in all subjects above the age of 60 years.

Exogenous monoterpene like limonene is sourced to breath from clinical environment or via recently consumed fruit juice or similar. Acetonitrile and aromatics such as furan, benzene and toluene etc. are exposed from the environment and/or smoking habits[21, 56]. These substances are lipophilic in nature and are stored in the fatty tissues. They mimicked the isoprene exhalation mainly due to having similar physio-chemical properties (e.g. low aqueous solubility, high volatility etc.) and compartmental storage.

While considering the limitations, our pilot study is conducted on a limited sample size and only on healthy adults and elderly subjects. Assuming this setup on a large population of age, gender and BMI matched healthy and sick subjects (including children) could enhance our clinical understanding on the observed adverse effects beyond the everlasting physiological (intra- and inter individual) variations in patient suffering from obstructive and restrictive lung conditions and other respiratory diseases. In elderly cohort, we had to limit the measurements within 15 min as most of them reached a $\mathrm{SpO}_{2}$ level < 94 by then under FFP2 masks. In our setup, we did not measure the fraction of exhaled nitric oxide (FeNO), which is known to regulate vasomotor tone, blood pressure and is regarded as a marker for oxidative stress[57]. The FeNO in breath increases under acute exogenous hypoxia[58] and pilot findings have indicated inverse relationship between isoprene and nitric oxide[59]. Thus, future examination of breath NO under the same/improved experimental conditions may reveal its clearer relationship to isoprene and other endogenous VOCs that are associated with oxidative stress and systemic microbial activity.

In conclusion, real-time breathomics has revealed a deeper insight into the physio-metabolic side effects of face-mask wearing. Based on recent pilot observations of cardiopulmonary parameters during exercise and rest in 12 healthy adults[7], researchers have generally recommended the continuous mask use. Within our setup, we have investigated the respiratory-, hemodynamic- and down-stream metabolic changes in adults and elderly subjects. Although we observed significant side effects and good compensation/adaptation trends in healthy adults below the age 60 years, those side effects emerged profoundly towards substantial risk in subjects over the age of 60 years within $15 \mathrm{~min}$. Mask induced deoxygenation (leading towards hypoxia i.e. $\mathrm{SpO}_{2}<90 \%$ ), deteriorating ventilation (leading towards hypoventilation i.e. $\mathrm{pET}-\mathrm{CO}_{2}>45 \mathrm{mmHg}$ ), compartmental vasoconstrictions and blood pressure alterations in elderly individuals turned out to be concerning upon the general health/clinical status under prolonged use of FFP2 face-masks at rest. Our pilot findings (in healthy cohorts) underline the importance of further large-scale clinical investigations of face-masks driven risk 
factors (i.e. clinically relevant) in patients with various cardio-respiratory diseases/conditions and in children. These results could help to intelligibly remodel the COVID-19 pandemic health policies, globally.

\section{References}

1. Kwon S, Joshi AD, Lo C-H, Drew DA, Nguyen LH, Guo C-G, Ma W, Mehta RS, Shebl FM, Warner ET, Astley CM, Merino J, Murray B, Wolf J, Ourselin S, Steves CJ, Spector TD, Hart JE, Song M, VoPham T, Chan AT. Association of social distancing and face mask use with risk of COVID-19. Nat. Commun. 2021; 12: 3737.

2. Brooks JT, Butler JC. Effectiveness of Mask Wearing to Control Community Spread of SARS-CoV-2. JAMA 2021; 325: 998.

3. Howard J, Huang A, Li Z, Tufekci Z, Zdimal V, Westhuizen H-M van der, Delft A von, Price A, Fridman L, Tang L-H, Tang V, Watson GL, Bax CE, Shaikh R, Questier F, Hernandez D, Chu LF, Ramirez CM, Rimoin AW. An evidence review of face masks against COVID19. Proc. Natl. Acad. Sci. [Internet] National Academy of Sciences; 2021 [cited 2021 Jul 20]; 118Available from: https://www.pnas.org/content/118/4/e2014564118.

4. Esposito S, Principi N, Leung CC, Migliori GB. Universal use of face masks for success against COVID-19: evidence and implications for prevention policies. Eur. Respir. J. [Internet] European Respiratory Society; 2020 [cited 2021 Jul 20]; 55Available from: https://erj.ersjournals.com/content/55/6/2001260.

5. Lässing J, Falz R, Pökel C, Fikenzer S, Laufs U, Schulze A, Hölldobler N, Rüdrich P, Busse M. Effects of surgical face masks on cardiopulmonary parameters during steady state exercise. Sci. Rep. 2020; 10: 22363.

6. Fikenzer S, Uhe T, Lavall D, Rudolph U, Falz R, Busse M, Hepp P, Laufs U. Effects of surgical and FFP2/N95 face masks on cardiopulmonary exercise capacity. Clin. Res. Cardiol. 2020; 109: 1522-1530.

7. Mapelli M, Salvioni E, Martino FD, Mattavelli I, Gugliandolo P, Vignati C, Farina S, Palermo P, Campodonico J, Maragna R, Russo GL, Bonomi A, Sciomer S, Agostoni P. "You can leave your mask on": effects on cardiopulmonary parameters of different airway protective masks at rest and during maximal exercise. Eur. Respir. J. [Internet] European Respiratory Society; 2021 [cited 2021 Sep 23]; 58Available from: https://erj.ersjournals.com/content/58/3/2004473.

8. Soriano JB, Anzueto A, Anticevich SB, Kaplan A, Miravitlles M, Usmani O, Papadopoulos NG, Puggioni F, Canonica GW, Roche N. Face masks, respiratory patients and COVID-19. Eur. Respir. J. [Internet] European Respiratory Society; 2020 [cited 2021 Jul 20]; 56Available from: https://erj.ersjournals.com/content/56/5/2003325.

9. Kisielinski K, Giboni P, Prescher A, Klosterhalfen B, Graessel D, Funken S, Kempski O, Hirsch O. Is a Mask That Covers the Mouth and Nose Free from Undesirable Side Effects in Everyday Use and Free of Potential Hazards? Int. J. Environ. Res. Public. Health Multidisciplinary Digital Publishing Institute; 2021; 18: 4344.

10. Kox M, van Eijk LT, Zwaag J, van den Wildenberg J, Sweep FCGJ, van der Hoeven JG, Pickkers P. Voluntary activation of the sympathetic nervous system and attenuation of the innate immune response in humans. Proc. Natl. Acad. Sci. U. S. A. 2014; 111: 7379-7384.

11. Vassilakopoulos T, Roussos C, Zakynthinos S. The immune response to resistive breathing. Eur. Respir. J. European Respiratory Society; 2004; 24: 1033-1043.

12. Galla JH. Metabolic Alkalosis. J. Am. Soc. Nephrol. American Society of Nephrology; 2000; 11: 369-375.

13. Sukul P, Schubert JK, Zanaty K, Trefz P, Sinha A, Kamysek S, Miekisch W. Exhaled breath compositions under varying respiratory rhythms reflects ventilatory variations: translating breathomics towards respiratory medicine. Sci. Rep. 2020; 10: 14109.

14. Sukul P, Schubert JK, Oertel P, Kamysek S, Taunk K, Trefz P, Miekisch W. FEV manoeuvre induced changes in breath VOC compositions: an unconventional view on lung function tests. Sci. Rep. 2016; 6: 28029.

15. Sukul P, Trefz P, Schubert JK, Miekisch W. Immediate effects of breath holding maneuvers onto composition of exhaled breath. J. Breath Res. 2014; 8: 037102.

16. King J, Koc H, Unterkofler K, Mochalski P, Kupferthaler A, Teschl G, Teschl S, Hinterhuber H, Amann A. Physiological modeling of isoprene dynamics in exhaled breath. J. Theor. Biol. 2010; 267: 626-637.

17. King J, Kupferthaler A, Frauscher B, Hackner H, Unterkofler K, Teschl G, Hinterhuber H, Amann A, Högl B. Measurement of endogenous acetone and isoprene in exhaled breath during sleep. Physiol. Meas. 2012; 33: 413-428.

18. Sukul P, Schubert JK, Trefz P, Miekisch W. Natural menstrual rhythm and oral contraception diversely affect exhaled breath compositions. Sci. Rep. 2018; 8: 10838. 
19. Trefz P, Schmidt SC, Sukul P, Schubert JK, Miekisch W, Fischer D-C. Non-Invasive Assessment of Metabolic Adaptation in Paediatric Patients Suffering from Type 1 Diabetes Mellitus. J. Clin. Med. [Internet] 2019 [cited 2020 Jul 18]; 8Available from: https://www.ncbi.nlm.nih.gov/pmc/articles/PMC6912469/.

20. Sukul P, Trefz P, Kamysek S, Schubert JK, Miekisch W. Instant effects of changing body positions on compositions of exhaled breath. J. Breath Res. 2015; 9: 047105.

21. Sukul P, Oertel P, Kamysek S, Trefz P. Oral or nasal breathing? Real-time effects of switching sampling route onto exhaled VOC concentrations. J. Breath Res. 2017; 11: 027101.

22. Herbig J, Müller M, Schallhart S, Titzmann T, Graus M, Hansel A. On-line breath analysis with PTR-TOF. J. Breath Res. 2009; 3 : 027004.

23. Trefz P, Schubert JK, Miekisch W. Effects of humidity, $\mathrm{CO} 2$ and 02 on real-time quantitation of breath biomarkers by means of PTR-ToF-MS. J. Breath Res. 2018; 12: 026016.

24. Löser B, Grabenschröer A, Pugliese G, Sukul P, Trefz P, Schubert JK, Miekisch W. Changes of Exhaled Volatile Organic Compounds in Postoperative Patients Undergoing Analgesic Treatment: A Prospective Observational Study. Metabolites Multidisciplinary Digital Publishing Institute; 2020; 10: 321.

25. Trefz P, Schmidt M, Oertel P, Obermeier J, Brock B, Kamysek S, Dunkl J, Zimmermann R, Schubert JK, Miekisch W. Continuous real time breath gas monitoring in the clinical environment by proton-transfer-reaction-time-of-flight-mass spectrometry. Anal. Chem. 2013; 85: 10321-10329.

26. Beder A, Büyükkoçak U, Sabuncuoğlu H, Keskil ZA, Keskil S. Preliminary report on surgical mask induced deoxygenation during major surgery. Neurocir. Astur. Spain 2008; 19: 121-126.

27. Smith CL, Whitelaw JL, Davies B. Carbon dioxide rebreathing in respiratory protective devices: influence of speech and work rate in full-face masks. Ergonomics 2013; 56: 781-790.

28. Rhee MSM, Lindquist CD, Silvestrini MT, Chan AC, Ong JJY, Sharma VK. Carbon dioxide increases with face masks but remains below short-term NIOSH limits. BMC Infect. Dis. 2021; 21: 354.

29. McGarry T, Biniecka M, Veale DJ, Fearon U. Hypoxia, oxidative stress and inflammation. Free Radic. Biol. Med. 2018; 125: 15-24.

30. Debevec T, Millet GP, Pialoux V. Hypoxia-Induced Oxidative Stress Modulation with Physical Activity. Front. Physiol. $2017 ;$ 8: 84.

31. Grimsrud PA, Xie H, Griffin TJ, Bernlohr DA. Oxidative Stress and Covalent Modification of Protein with Bioactive Aldehydes. J. Biol. Chem. 2008; 283: 21837-21841.

32. Giordano FJ. Oxygen, oxidative stress, hypoxia, and heart failure. J. Clin. Invest. American Society for Clinical Investigation; 2005; 115: 500-508.

33. Cooke MS, Evans MD, Dizdaroglu M, Lunec J. Oxidative DNA damage: mechanisms, mutation, and disease. FASEB J. 2003; 17: 1195-1214.

34. Reuter S, Gupta SC, Chaturvedi MM, Aggarwal BB. Oxidative stress, inflammation, and cancer: How are they linked? Free Radic. Biol. Med. 2010; 49: 1603-1616.

35. Stevens JF, Maier CS. Acrolein: sources, metabolism, and biomolecular interactions relevant to human health and disease. Mol. Nutr. Food Res. 2008; 52: 7-25.

36. Tangerman A. Measurement and biological significance of the volatile sulfur compounds hydrogen sulfide, methanethiol and dimethyl sulfide in various biological matrices. J. Chromatogr. B 2009; 877: 3366-3377.

37. Han N, Pan Z, Liu G, Yang R, Yujing B. Hypoxia: The “Invisible Pusher” of Gut Microbiota. Front. Microbiol. 2021; 12: 2012.

38. Singhal R, Shah YM. Oxygen battle in the gut: Hypoxia and hypoxia-inducible factors in metabolic and inflammatory responses in the intestine. J. Biol. Chem. 2020; 295: 10493-10505.

39. Silva YP, Bernardi A, Frozza RL. The Role of Short-Chain Fatty Acids From Gut Microbiota in Gut-Brain Communication. Front. Endocrinol. [Internet] Frontiers; 2020 [cited 2021 May 24]; 11Available from: https://www.frontiersin.org/articles/10.3389/fendo.2020.00025/full.

40. Wang L, Cen S, Wang G, Lee Y, Zhao J, Zhang H, Chen W. Acetic acid and butyric acid released in large intestine play different roles in the alleviation of constipation. J. Funct. Foods 2020; 69: 103953.

41. Besten G den, Eunen K van, Groen AK, Venema K, Reijngoud D-J, Bakker BM. The role of short-chain fatty acids in the interplay between diet, gut microbiota, and host energy metabolism. J. Lipid Res. Elsevier; 2013; 54: 2325-2340. 
42. Miyamoto J, Kasubuchi M, Nakajima A, Irie J, Itoh H, Kimura I. The role of short-chain fatty acid on blood pressure regulation. Curr. Opin. Nephrol. Hypertens. 2016; 25: 379-383.

43. Jackson DC. Acid-base balance during hypoxic hypometabolism: selected vertebrate strategies. Respir. Physiol. Neurobiol. 2004; 141: 273-283.

44. Sukul P, Schubert JK, Kamysek S, Trefz P, Miekisch W. Applied upper-airway resistance instantly affects breath components: a unique insight into pulmonary medicine. J. Breath Res. 2017; 11: 047108.

45. Elshaghabee FMF, Bockelmann W, Meske D, de Vrese M, Walte H-G, Schrezenmeir J, Heller KJ. Ethanol Production by Selected Intestinal Microorganisms and Lactic Acid Bacteria Growing under Different Nutritional Conditions. Front. Microbiol. [Internet] 2016 [cited 2021 May 21]; 7Available from: https://www.ncbi.nlm.nih.gov/pmc/articles/PMC4732544/.

46. Logan BK, Jones AW. Endogenous ethanol "auto-brewery syndrome" as a drunk-driving defence challenge. Med. Sci. Law 2000; 40: $206-215$.

47. Elamin EE, Masclee AA, Dekker J, Jonkers DM. Ethanol metabolism and its effects on the intestinal epithelial barrier. Nutr. Rev. 2013; 71: 483-499.

48. Kalapos MP. On the mammalian acetone metabolism: from chemistry to clinical implications. Biochim. Biophys. Acta 2003; 1621: 122-139.

49. Mean Arterial Pressure - an overview / ScienceDirect Topics [Internet]. [cited 2021 Sep 13].Available from: https://www.sciencedirect.com/topics/agricultural-and-biological-sciences/mean-arterial-pressure.

50. Sukul P, Grzegorzewski S, Broderius C, Trefz P, Mittlmeier T, Fischer D-C, Miekisch W, Schubert JK. Breathomics of Healthy Female Aging: Physio-Metabolic Effects of Puberty, Teenage, Reproductive and Postmenopausal Life on Exhaled Biomarkers [Internet]. Rochester, NY: Social Science Research Network; 2021 JunReport No.: ID 3872038. Available from: https://papers.ssrn.com/abstract=3872038.

51. Sukul P, Richter A, Schubert JK, Miekisch W. Deficiency and absence of endogenous isoprene in adults, disqualified its putative origin. Heliyon 2021; 7: e05922.

52. Edwards AD, Jennings SJ, Newstead CG, Wolff CB. The effect of increased lung volume on the expiratory rate of rise of alveolar carbon dioxide tension in normal man. J. Physiol. 1983; 344: 81-88.

53. Lärstad M a. E, Torén K, Bake B, Olin A-C. Determination of ethane, pentane and isoprene in exhaled air-effects of breath-holding, flow rate and purified air. Acta Physiol. Oxf. Engl. 2007; 189: 87-98.

54. Xie A, Skatrud JB, Puleo DS, Morgan BJ. Exposure to hypoxia produces long-lasting sympathetic activation in humans. J. Appl. Physiol. American Physiological Society; 2001; 91: 1555-1562.

55. Dinenno FA. Hypoxic Regulation of Blood Flow in Humans. In: Roach RC, Wagner PD, Hackett PH, editors. Hypoxia Boston, MA: Springer US; 2003. p. 237-248.

56. Amann A, Costello B de L, Miekisch W, Schubert J, Buszewski B, Pleil J, Ratcliffe N, Risby T. The human volatilome: volatile organic compounds (VOCs) in exhaled breath, skin emanations, urine, feces and saliva. J. Breath Res. 2014; 8: 034001.

57. Pierini D, Bryan NS. Nitric oxide availability as a marker of oxidative stress. Methods Mol. Biol. Clifton NJ 2015; 1208: 63-71.

58. Dimov PK, Marinov BI, Ilchev IS, Taralov ZZ, Kostianev SS. Evaluation of Acute Exogenous Hypoxia Impact on the Fraction of Exhaled Nitric Oxide in Healthy Males. Folia Med. (Plovdiv) 2015; 57: 230-234.

59. Khan A, Staimer N, Tjoa T, Galassetti P, Blake DR, Delfino RJ. Relations between isoprene and nitric oxide in exhaled breath and the potential influence of outdoor ozone: a pilot study. J. Breath Res. 2013; 7: 036007.

\section{Declarations}

\section{Acknowledgements}

We thank all the volunteers for participating in this study.

The PTR-ToF-MS-8000 instrument used in this study was entirely funded by the European fund for regional development (EFRE). This study was partially funded by Marie-Curie $7^{\text {th }}$ European Community Framework ITN Programme (FP7-PEOPLE-ITN-PIMMS project, Grant agreement no. 287382). The funders had no role in study design, data collection and analysis, decision to publish or preparation of the manuscript. 
Authorship

P.S. and W.M. conceived the idea and along with J.K.S. planned the study. P.S., J.B., P.F., R.R. and L.R. recruited volunteers and performed experiments. P.S. and P.T. analysed data. P.S. prepared the results and performed statistical analysis. P.S., J.K.S. and S.K. contributed to clinical interpretation and discussion. W.M. contributed to analytical interpretations. P.S. wrote the manuscript, which was reviewed and edited by all authors. Correspondence and requests for materials should be addressed to P.S. (email:

pritam.sukul@uni-rostock.de).

\section{Data availability}

All raw data collected for the study will be made available to others after reasonable request. Data will be stored in anonymised form at online repository when the paper is published.

\section{Conflict of interest}

The authors have nothing to disclose.

Note

The human subject (visible in Fig. 1) has provided her informed consent for the publication of the image.

\section{Figures}

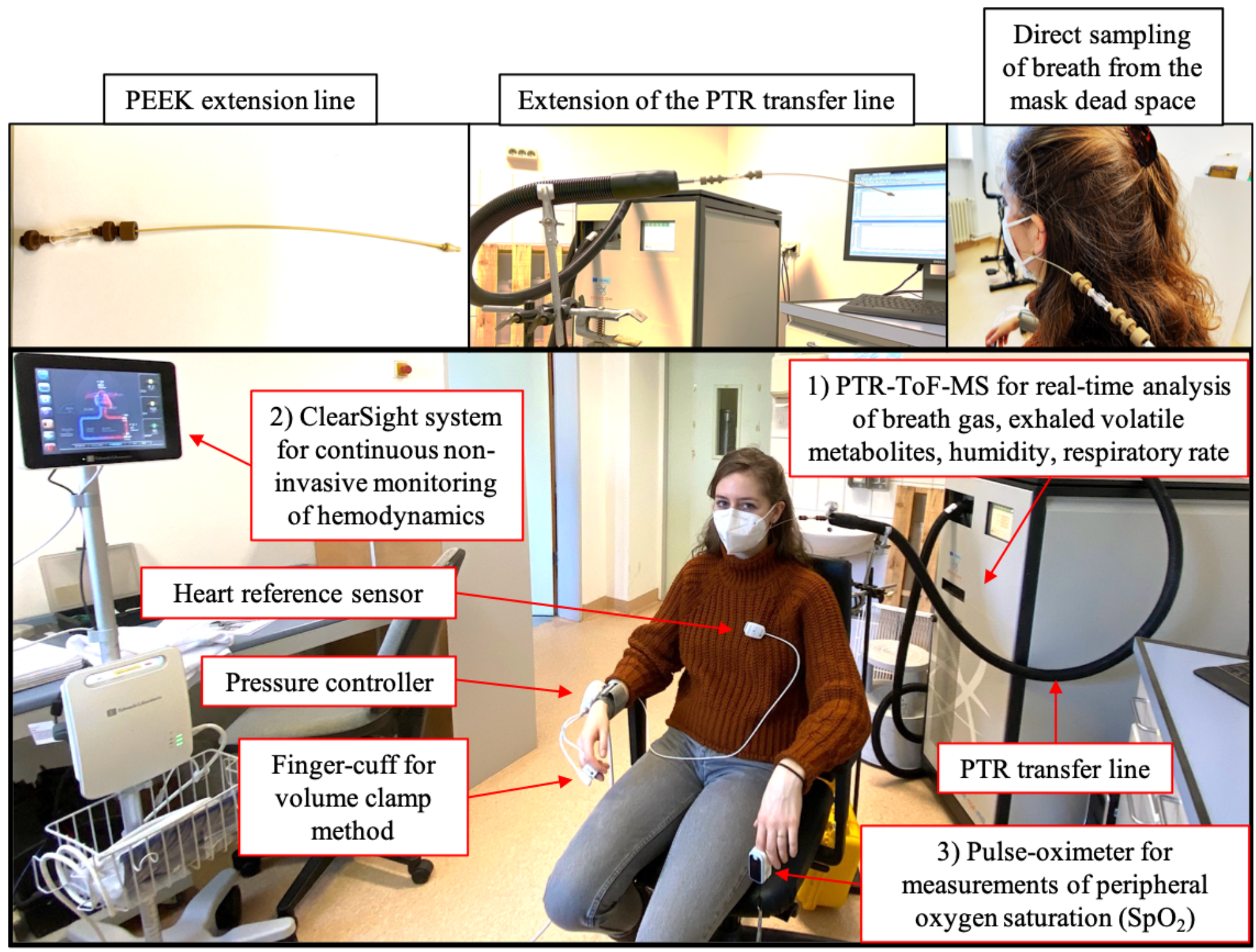




\section{Figure 1}

Instrumentation and experimental setup of the study. Customised PEEK extension of the PTR transfer line for direct sampling from the mask dead space is presented at the top. Continuous real-time breathomics via PTR-ToF-MS (1) in parallel to continuous non-invasive monitoring of haemodynamic via ClearSight system (2) and pulseoximetry (3) is presented at the bottom.

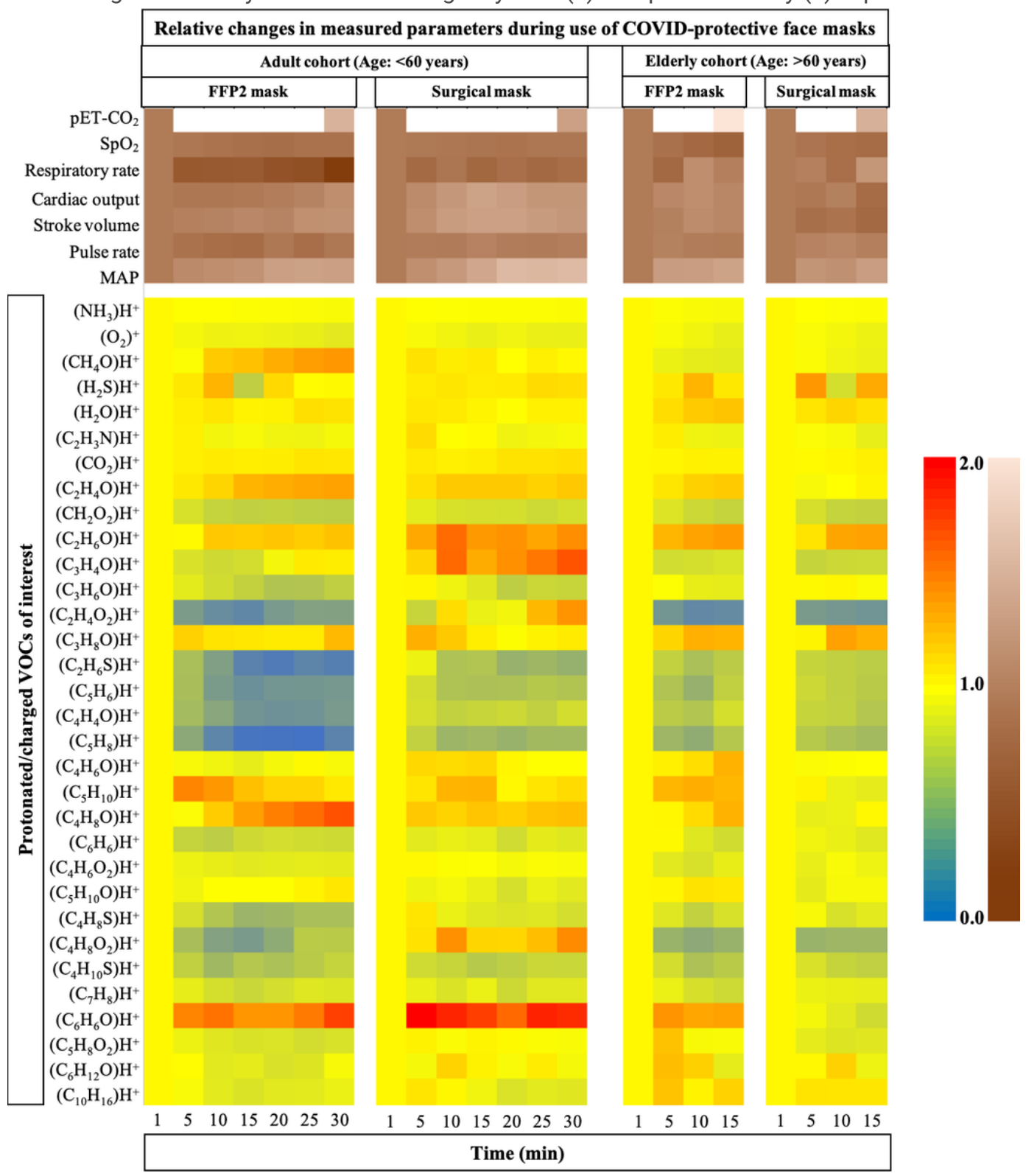

\section{Figure 2}

Relative changes in normalised mean values of physiological parameters and of exhaled alveolar VOC abundances during the use of COVID-protective face masks by healthy adult and elderly cohorts. Y-axis represents the physiological parameters viz. pET-CO2, SpO2, respiratory rate, cardiac output, stroke volume, pulse rate, mean arterial pressure (MAP) values and the protonated/charged VOCs of interest. X-axis indicates time in minutes. VOCs were tentatively identified according to their mass/charge ratio. For each individual, VOC data were normalised onto corresponding median values from the first minute. Respiratory-, haemodynamic parameters and $\mathrm{SpO} 2$ were normalised likewise. The mean of those normalised values from every 5th minute is presented here. Only pET-CO2 values are presented from immediately before and after mask use and are placed at the first and final minute of heatmaps. Red and blue colour symbolise relatively higher and lower abundances of VOCs, respectively. Similarly, light and dark colours symbolise relatively higher and lower values of physiological parameters, respectively. 

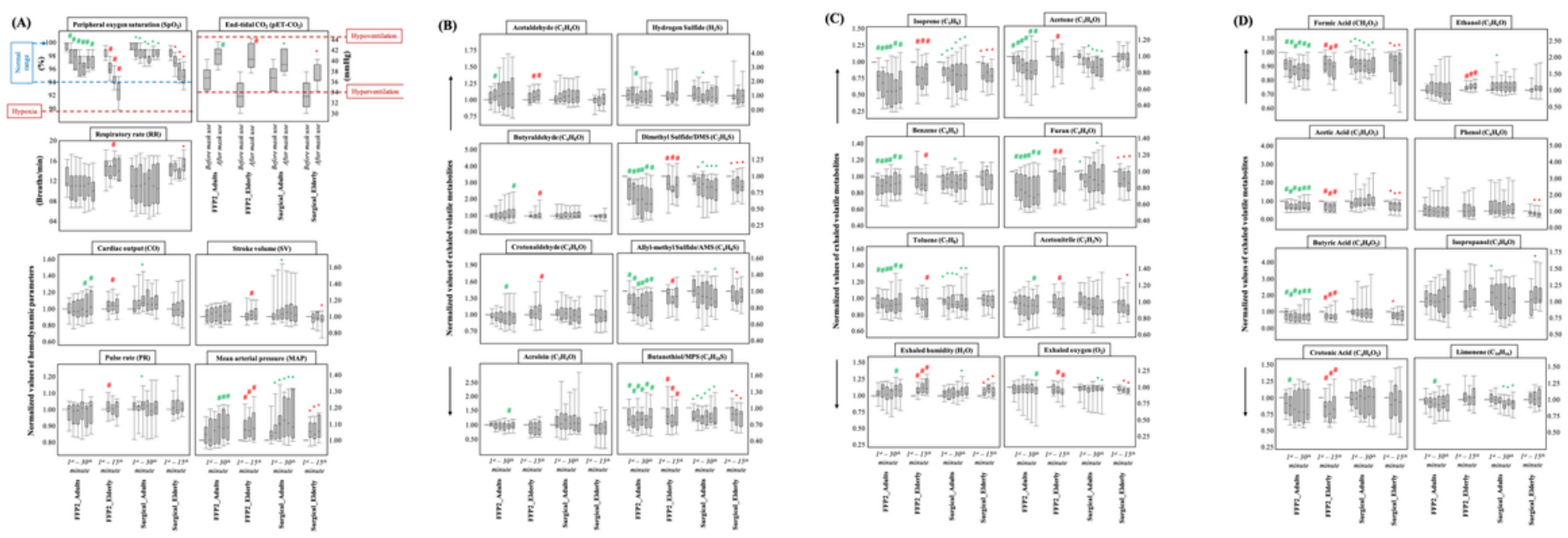

\section{Figure 3}

Comparison of differences in physiological parameters and in exhaled alveolar VOC concentrations during the use of COVID-protective face masks by healthy adult and elderly cohorts. (A) physiological parameters, (B) aliphatic aldehydes and organosulfur, (C) hemiterpene, ketone, nitrile, aromatics, exhaled humidity and oxygen (D) aliphatic acids, alcohols and monoterpene. $X$-axis represents measurement time in four groups viz. two mask types (FFP2 and surgical) used by two age cohorts (adults and elderly). Y-axis represents absolute values or normalised (onto corresponding initial values) values of measured parameters from every 5th minute, starting from the $1 \mathrm{st}$ minute. For both mask types, adults and elderly cohorts were measured for $30 \mathrm{~min}$ and 15 min, respectively. pET$\mathrm{CO} 2$ values are measured immediately before and after the use of masks. Measured values within each group were compared. Statistical significances were tested by means of repeated measurement-ANOVA on ranks ( $p$-value $\leq 0.005$ ). From all pairwise-multiple comparisons, statistically significant differences with respect to the '1st minute' are indicated via coloured '\#' and ' $*$ '. Here, \# and * are assigned to FFP2 and surgical masks, respectively. Green and red colours denote adults and elderly cohorts, respectively. Similarly, pET-CO2 values before and after mask use are compared statistically. 
(A)

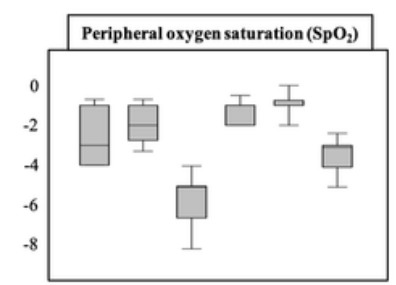

Respiratory rate (RR)
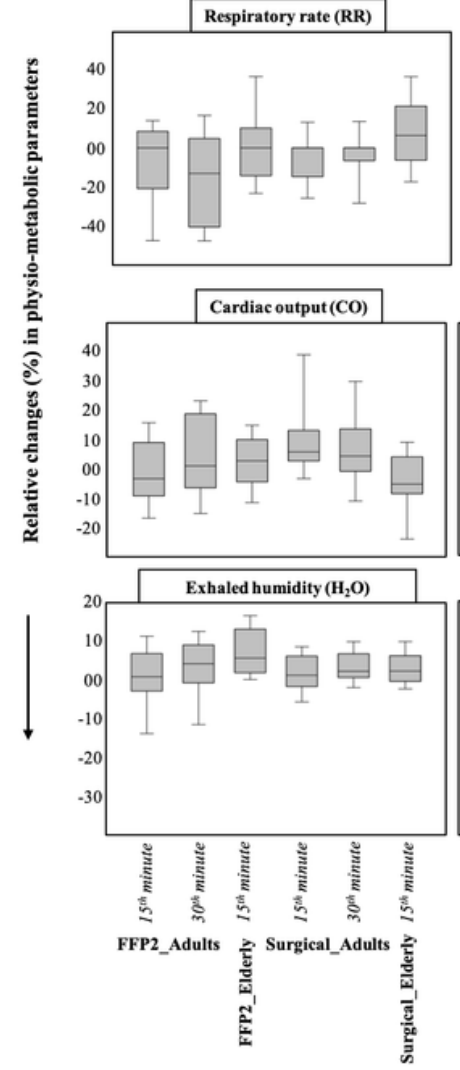

End-tidal $\mathrm{CO}_{2}\left(\mathrm{pET}-\mathrm{CO}_{2}\right)$

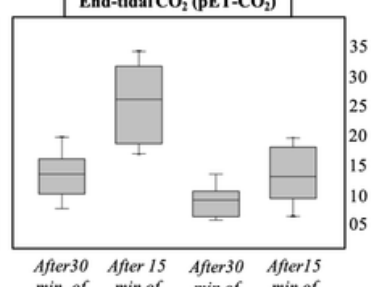

min of min of min of min of

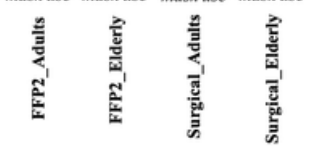

Mean arterial pressure (MAP)

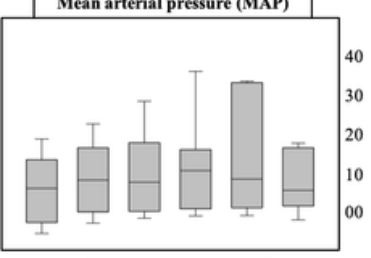

Exhaled oxygen $\left(\mathrm{O}_{2}\right)$

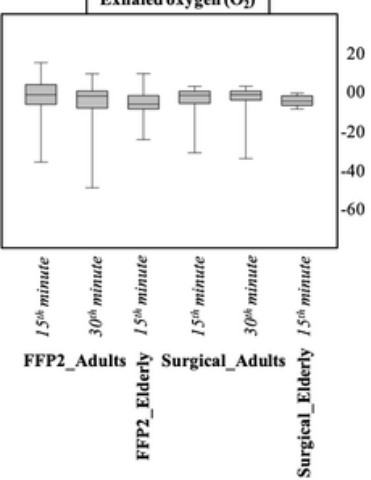

(B)
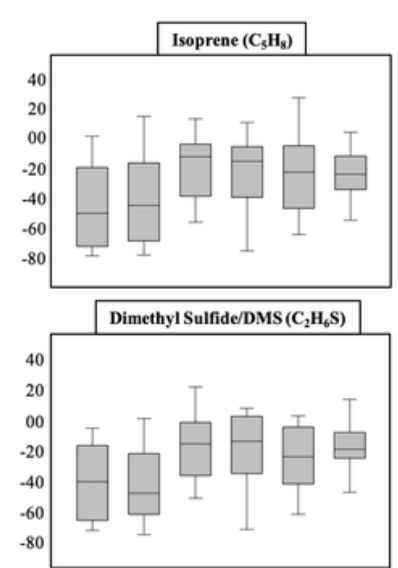

Acetaldehyde $\left(\mathrm{C}_{2} \mathrm{H}_{4} \mathrm{O}\right)$
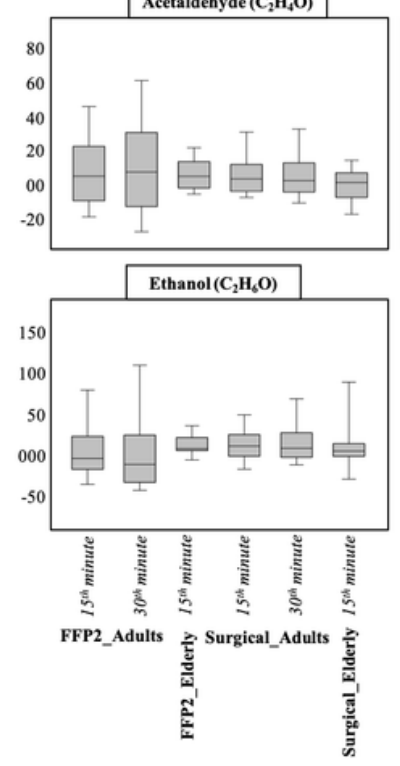

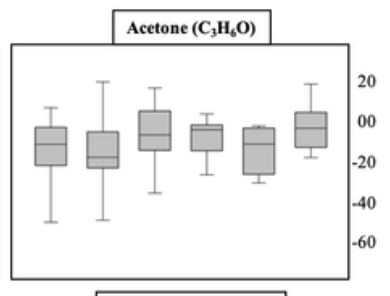

Acetic Acid $\left(\mathrm{C}_{2} \mathrm{H}_{4} \mathrm{O}_{2}\right)$

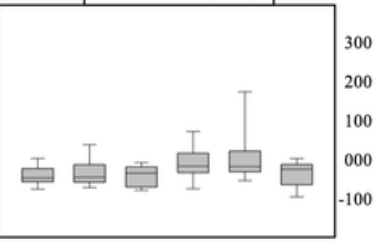

Limonene $\left(\mathrm{C}_{10} \mathrm{H}_{16}\right)$

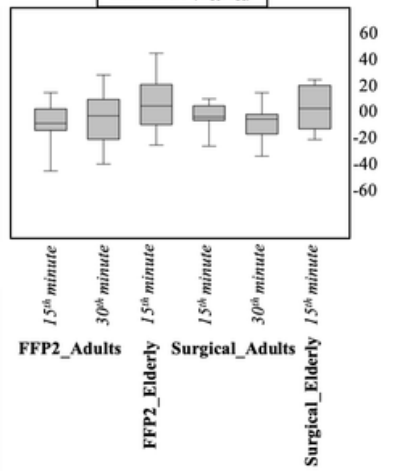

Figure 4

Comparison of relative changes (in \%) in physiological parameters and in exhaled metabolic markers during the use of COVIDprotective face masks by healthy adult and elderly cohorts. (A) Physio-metabolic parameters and (B) Exhaled alveolar volatile organic metabolites. X-axis represents measurement time in four groups viz. two mask types (FFP2 and surgical) used by two age cohorts (adults and elderly). Y-axis represents \% of changes (with respect to initial values) in measured parameters at 15th and/or 30th minute. For both mask types, adults and elderly cohorts were measured for $30 \mathrm{~min}$ and $15 \mathrm{~min}$, respectively. Thus, for both mask types, changes in adults at the 15th and 30th min are presented and the same is presented in elderly cohort at the 15th min. pET-CO2 values are measured immediately before and after the use of masks. Measured values within each group were compared. Statistical significances were tested by means of repeated measurement-ANOVA on ranks ( $p$-value $\leq 0.005$ ). Results from all pairwise-multiple comparisons are listed in Table 3.

\section{Supplementary Files}

This is a list of supplementary files associated with this preprint. Click to download.

- SupplementMaskstudySukul.pdf 